\title{
Goal setting
}

A new editor, a new publisher, a new beginning. Before we look to the future, however, we should recognise the achievements of the past and laud the evolution of the Journal under the guidance of my predecessors in the editorial chair. Henry Robson was synonymous with the Journal for many years and when reading the journal one felt that he had lovingly crafted almost every word himself. Sadly Henry is no longer with us, and his wife Ada died late last year, so ending long family links with the Journal. Peter Sperryn is the other major figure in the development of the Journal who almost single handedly brought it from its humble beginnings to its current international status. In the early days he did much of secretarial work and subediting himself during many hours, ensuring the Journal's publication through difficult times. He built links with many of the leading international figures of sports medicine and promoted the Journal enthusiastically worldwide. Those who attended great esteem in which he is held by the BASM membership for his outstanding contribution to the Journal, but Peter has been an inspiration to an entire generation of sports medicine not alone through his dedication to the Journal but through his writing and teaching. We all hope he will continue in this mission. One of his last major achievements as editor was bringing the Journal to BMJ publications and it was this vision and foresight that ensures its future success. It is a great honour to be his successor and I am very grateful for his warm and enthusiastic encouragement. Adrienne Hardman, Wendy Dodds, Clyde Williams, and Dan Tunstall Pedoe also held the reins at the Journal during periods of transition and I am delighted that both Clyde Williams and Dan Tunstall Pedoe remain on the editorial board to steady my hand on the tiller.

And so to the future. This first editorial is an opportunity to lay out my plans for the coming years. While I see great opportunities to develop the Journal, the changes will occur by evolution rather than revolution. If you are an academic, a clinician, or simply have interest in sports medicine I hope that you will find these changes meet your needs. If you do not agree with the changes you can be assured that I am open to any advice, suggestions, or even the occasional grumble, so feel free to speak to me personally or open a dialogue in the correspondence section of the Journal. In this first issue you will find some minor changes and in future issues there will be further the 1995 BASM annual congress were witness to the

invited editorials by local and international experts on topics of clinical, scientific, and educational interest. We also aim to publish review articles addressing, in particular, the medical benefits of exercise and the management of clinical problems. The academic papers will always be the core content of any journal and we shall be making a special effort to attract high quality manuscripts. One of the most exciting developments in British sports medicine has been the growth in university based academic departments and, while this will undoubtedly improve teaching in the discipline, these departments also have a responsibility to initiative high quality research and in this we can assure them of a voice. Of course there will always be a place for the individual clinician and we would encourage submission of case reports and clinical case series from your everyday work. The Journal will also publish peer reviewed abstracts from the shorts papers section of the BASM annual congress, the major academic meeting for sports medicine in the United Kingdom. The congress provides an opportunity to present new work and we hope by publishing these abstracts we can encourage increased support and foster academic development. We shall also audit our own performance and aim to speed up the time from submission to publication. So that you can see how we are doing we will begin to publish dates of submission and acceptance of papers but there is currently a backlog of accepted papers which will take some time to clear.

The academic standing of the journal depends on the quality of papers, but there are many human interest stories in sport and sports medicine which add to the rich tapestry of sporting life. Articles of general and historical interest, anecdotes or essays on items of relevance to sport and medicine may be published on their own merits or as fillers. This has been a very successful formula in other journals and adds greatly to the readability of the Journal. It will not in any way distract us from our academic objectives, but sport has a broad palette and we can paint a brighter picture by adding some colour. Our ambitions can only be realised if we have the material and we can only publish high quality work if it is submitted. The academic standard, the impact factor, and the enjoyment we all get from the Journal depends on you. I am only the conductor of the orchestra, you are the musicians.

DOMHNALL MACAULEY Editor

\section{The future of sports medicine}

This is an exciting time to be involved in exercise science and sports medicine. Professional and public interest in our field is greater than ever, and many exciting developments and activities are under way. When I was beginning my career nearly 30 years ago, exercise science was not a respectable area of investigation in academic circles. There was little good research under way, there were few quality graduate educational programmes, and funding for research in this field was essentially nonexistent. Fortunately, all these things changed. Exercise science now encompasses disciplines from molecular biology to epidemiology, with important basic contri- 
butions being made to promote a better understanding of physiology and knowledge about the importance of regular physical activity to health.

My own area of interest is in the epidemiology of physical activity as it relates to health, and in the application of this information to improve public health. Pioneering investigations on the role of sedentary habits in the development of heart disease by Professor Jerry Morris in the United Kingdom nearly 40 years ago led the way in establishing inactivity as an important risk factor for disease. We now have substantial evidence that lack of exercise leads to the development of heart disease, some cancers, type II diabetes, stroke, and certain musculoskeletal disorders. It is becoming increasingly clear that a physically active way of life enhances feelings of general wellbeing and generally improved psychosocial health.

The impressive body of evidence on physical activity and health led many organisations around the world to develop initiatives and statements on this topic. Organisations such as the World Health Organisation, International Federation of Sports Medicine, American Heart Association, and American College of Sports Medicine issued statements on this topic within the past few years.

We made enormous progress in sports medicine and exercise science over the past 40 years, but what does the future hold?

Physical activity and health - I think that we will make important additional advances in understanding the role of sedendary living in disease development. Exciting new work on exercise and immune function, and how this relates to risk of cancer and other diseases, is one prominent example. I think we can now conclude that physical inactivity does indeed increase risk of colon cancer, and probably has a role in the development of breast and prostate cancer as well. In fact, I predict that over the next decade or two we will learn that the population attributable risk of physical activity for cancer is greater than the attributable risk of diet for this outcome.

Physical activity dose-response - We now know that physical activity has many health benefits, but we still do not have enough information about the specific type, intensity, and total amount of activity that is required for protection. It is clear that there is a dose-response gradient of health benefits across physical activity and physical fitness strata, and we need to learn much more about the specific shape of these curves for different endpoints. One of the current major research issues is in regard to the relation of different exercise intensities to health and functional outcomes. Many talented scientists are working on this issue, and I am confident that answers will be forthcoming.

\section{Sport and exercise medicine}

The recognition of sport and exercise medicine in Britain as a substantive specialist interest for medical graduates is facing a critical period in its development.

The Prime Minister, a great lover of sport at all levels, personally launched the government's sports policy paper "Sport: Raising the Game" in July $1995 .{ }^{1}$ This paper makes it clear that the Government would like to promote a British Academy of Sport. A subsequent consultative
Physical activity and behavioural science - The roots of exercise science are in the physiological disciplines. The great British physiologist A V Hill won the Nobel Prize for his research in exercise physiology in the early part of this century. As indicated earlier, much important current investigation is underway in exercise physiology, and these efforts will undoubtedly continue to produce important results. From a public health perspective, one of the most significant issues is how to get more people more active more of the time. We do not have enough information on successful physical interventions. Fortunately, in recent years psychologists and other behavioural scientists turned their attention to issues in physical activity. Much of the current work in this area is based on well developed theories of behaviour change, and much new information is being generated. I think that the next few years will produce tremendous advances in our understanding of how to implement successful physical activity interventions.

A major unresolved issue relating to physical inactivity and public health is the effect of the social and physical environments in which those of us in industrialised societies live. We have spent the past 50 or more years systematically engineering the need for human energy expenditure to minimal levels. Professor James estimates that the average decline in daily energy expenditure in the United Kingdom is $800 \mathrm{kcal}$ over the past 20 years. ${ }^{1}$ This trend is likely to continue. What can be done? Our citizens in industrialised societies are not likely to shun sedentary recreational activities such as television viewing and surfing the internet, nor is it reasonable that they will give up most labour saving devices at home and at work. If Professor James is correct, the average individual in the UK would have to add a daily walk of eight miles to compensate for the decrease in average energy expenditure. It does not seem probable that any intervention programme is likely to produce an increase of activity of this magnitude in the population.

Thus, although we have made much progress in exercise science and sports medicine, and exciting new discoveries are constantly made, major challenges are ahead in terms of physical activity and health. Humans evolved to be active animals, and we may be physiologically unsuited to life in modern society. I believe that the high prevalence of physical inactivity in many countries around the world is one of the most serious threats to health we face. Let us hope that by working together we can learn to surmount this problem.

STEVEN N BLAIR

President-elect, American College of Sports Medicine Cooper Institute for Aerobic Resarch

1 James WPT. A public health approach to the problem of obesity. Int $\mathcal{f}$ Obes 1995;19(suppl 3):S37-45.

document entitled "The British Academy of Sport" was released by the Sports Council early in December $1995 .^{2}$ As with all such documents, the consultative period was disappointingly brief, closing on 31 January 1996.

The development of an infrastructure to support and promote excellence in sport is a key section in the consultative document. The importance of quality sports medicine and sports science is clearly identified. These 